\title{
Lead in Bones and Drinking Water in Towns with Hard and Soft Water
}

\author{
M. D. CRAWFORD, D. G. CLAYTON
}

British Medical fournal, 1973, 2, 21-23

\begin{abstract}
Summary
In two comparable series of medicolegal necropsies the lead content of ribs was found to be much higher in three soft water than in three hard water towns in England and Wales. Fourteen out of 96 "overnight" tap water samples from five soft water and five hard water towns in England and Wales and from Glasgow (soft water) had lead concentrations of over 0.1 p.p.m.; values over 0.3 p.p.m. were found only in Glasgow. The possible relevance of the findings to the association of cardiovascular disease and soft drinking water is discussed.
\end{abstract}

\section{Introduction}

Investigations into possible causes of the higher death rates from cardiovascular disease in soft water compared with hard water areas in the U.K. have considered the possibility that these might be, in part, due to the carriage by soft waters of metal contaminants, lead especially, from pipes into supply. Lead values considerably over conventional safety limits were reported in "overnight" water from consumers' taps, particularly in some soft water towns (Crawford and Morris, 1967). Later, the lead content of the ribs from two comparable series of medicolegal necropsies was found to be much higher in Glasgow with a soft water than in London with a hard water supply (Crawford and Crawford, 1969).

Further studies of bone lead and trace elements in drinking water have now been carried out as part of a series of related studies probing the water factor in cardiovascular disease in 12 towns of England and Wales, six with hard water and six with soft water.

\section{Materials and Methods}

Details of the study towns are published elsewhere (Stitt et al., 1973). Portions of rib were available over a period of about 18 months from necropsies of cases at ages 30 to 59 where the death was sudden. Altogether, 55 ribs-27 from three towns with hard water and 28 from three towns with soft water-from patients who died of ischaemic heart disease ( 31 cases) and "other" causes ( 24 cases) were analysed for lead. The "other" causes were accident (14 cases) and miscellaneous causes of sudden death unrelated to "heart" disease-for instance, perforated ulcer, subarachnoid haemorrhage (10 cases). Each case from the "other" group was matched for age and sex by one or two ischaemic heart disease cases from the same town, and the grouped samples for hard water and soft water towns were matched for age, sex, and cause of death (ischaemic heart disease $v$. "other"). There were 36 ribs from males and 19 from females. The ischaemic heart disease patients had

M.R.C. Social Medicine Unit, Public Health Department, London School of Hygiene and Tropical Medicine, London WC1E 7HT M. D. CRAWFORD, M.D., M.R.C.P., Member of Scientific Staff D. G. CLAYTON, M.A., Member of Scientific Staff no previous history of heart trouble-that is, presented as "sudden death." All patients had resided in the study town for 10 or more years and most had lived there much of their lives.

The analytical division of the Atomic Energy Research Establishment carried out the assays for lead in the rib samples by absorptiometry, after a preliminary feasibility study of seven different methods (Hislop et al., 1973). The data for the earlier study of bone lead in Glasgow and London (Crawford and Crawford, 1969) were reassessed for comparison.

Ninety-six tap water samples-the first run-off in the morning - were obtained, 39 in five of the hard water and 44 in five of the soft water study towns and 13 in Glasgow. Standard chemical analyses for drinking water and analyses for 22 trace elements were carried out on these samples by the Counties' Public Health Laboratories. The lead results only are presented here; other trace elements will be reported later.

\section{Results}

Bones.-The mean lead content of the ribs from the six towns, expressed as p.p.m. dried ash, is shown in table I. The mean value is much higher for the soft water towns $(P<0.005)$. There was an anomalous value of 98 p.p.m. for a sample from

TABLE I-Lead Content of Rib Bone Samples

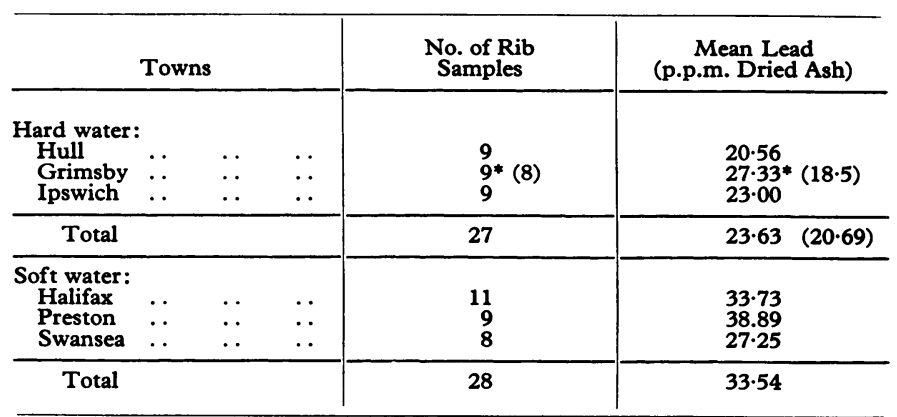

*This includes one value of 98 p.p.m. (see text). Mean lead with this value excluded given in parentheses.

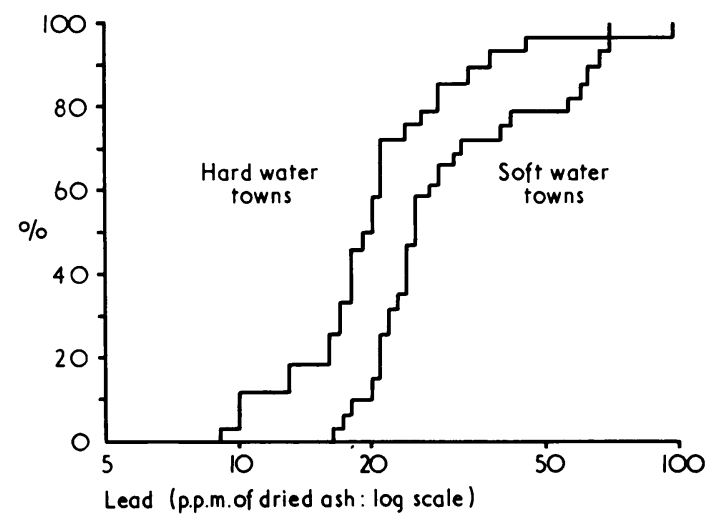

FIG. 1-Cumulative distribution of lead in 55 rib samples in three hard water and three soft water towns. 
TABLE II-Distribution of Lead Levels in Overnight Water of Inhabited Houses in 10 County Boroughs of England and Wales and in Glasgow, 1971

\begin{tabular}{|c|c|c|c|c|c|c|}
\hline & \multirow{2}{*}{$\begin{array}{c}\text { No. of } \\
\text { Samples }\end{array}$} & \multicolumn{5}{|c|}{ Lead (p.p.m.) } \\
\hline & & $<0.05$ & $0.05-0.09$ & $0.10-0.19$ & $0.20-0.29$ & 0.30 and over \\
\hline $\begin{array}{l}5 \text { Hard water towns* (average hardness } 291 \text { p.p.m. } \mathrm{CaCO}_{2} \text { ) } \\
5 \text { Soft water townst (average hardness } 37 \text { p.p.m. CaCO } \\
\text { Glasgow (average hardness } 10 \text { p.p.m. CaCOs }{ }_{3} \text { ) } . .\end{array}$ & $\begin{array}{l}39 \\
44 \\
13\end{array}$ & $\begin{array}{r}32 \\
37 \\
2\end{array}$ & $\begin{array}{l}4 \\
5 \\
2\end{array}$ & $\begin{array}{l}3 \\
2 \\
4\end{array}$ & 3 & 2 \\
\hline
\end{tabular}

*Towns of table I plus Norwich and Reading.

†Towns of table I plus Bradford and Salford.

Grimsby, possibly the result of occupational exposure as the deceased man had been a boiler maker. If this case is excluded there is no overlap in the means for the soft and hard water towns. A clear separation between the cumulative distributions of bone lead in the two groups of towns is shown in fig. 1; the whole distribution in the soft water towns is shifted to the right. In the earlier study of comparable cases in Glasgow and London the mean rib concentrations were 83 p.p.m. and 44 p.p.m. (dried weight of bone) respectively (Crawford and Crawford 1969). A similar

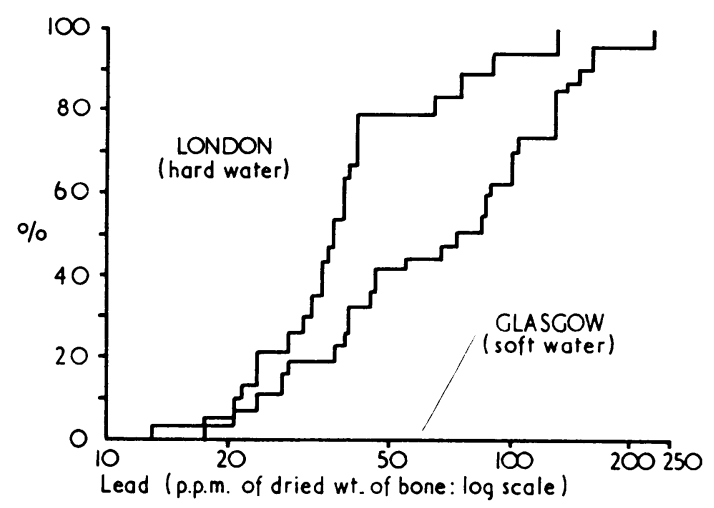

FIG. 2-Cumulative distribution of lead in $\mathbf{4 6}$ rib samples in London and Glasgow.

shift to the right in the Glasgow distribution in the 46 cases aged 30-59 from that study is shown in fig. 2, many of them having high values-that is, over 100 p.p.m. These findings indicate that the substantial difference between the mean values in both studies are not due to a few cases with very high levels. Consistent differences in the lead concentrations in the ribs from the ischaemic heart disease compared with the "other" cases were not found in the present study. However, analyses of the data for men aged 30-59 from the earlier study showed much higher values for the ischaemic heart disease compared with the accident cases in Glasgow (soft water).

Water.-The mean lead concentrations of the overnight samples from the five soft water and the five hard water towns of England and Wales were the same, 0.03 p.p.m., and were well within the conventional safety limit of 0.1 p.p.m. (World Health Organization, 1971). The distribution of lead concentrations in the water of these two groups of towns and also in the samples of Glasgow water is shown in table II. The distribution of lead is similar in the grouped soft and hard water towns. There are now no samples from these towns with very high concentrations -that is, over 0.3 p.p.m. - as was found in a previous study in which some of these towns were included (Crawford and Morris, 1967). Five of the 83 samples, however, still had lead values over $0 \cdot 1$ p.p.m. The lead concentrations in nine of the 13 samples from Glasgow are over 0.1 p.p.m. and two are over 0.3 p.p.m. suggesting that there is still a considerable plumbosulvency problem in that city.

\section{Discussion}

The present findings suggest that people living in soft water areas have higher concentrations of lead in their bones than those living in hard water areas. Lead accumulates in bones when exposure exceeds elimination, and though many factors, such as industrial exposure or contact with lead paints in childhood, may explain high concentrations in individuals the present findings indicate a more generally distributed cause; the ingestion of small doses of lead from drinking water over a long period of time is a possible explanation. Outbreaks of actual lead poisoning from plumbosolvency have occurred from time to time in soft water areas and though measures to counteract plumbosolvency have been applied by many water undertakings over several decades there have been repeated reports in recent years of lead concentrations well above accepted limits in some drinking waters (Wilson, 1966, 1967; Crawford and Morris, 1967; Reed and Tolley, 1971). In Glasgow, with extremely soft water, there is evidence from the present and other studies that there is still a considerable pick-up of lead. In an analysis of 84 routine samples 20 $(24 \%)$ had lead concentrations of over 0.1 p.p.m. and four had concentrations of over 0.3 p.p.m. (W. J. Patterson, personal ccmmunication, 1971), and Beattie et al. (1972) found high blood lead levels in Glasgow families living in houses with lead piping and a correlation between the blood lead concentrations and the length of lead piping in the distribution system of their houses. The unusually plumbosolvent nature of the Glasgow water supply may have contributed to differences found in an earlier study comparing the prevalence of coronary artery and myocardial disease in Glasgow and London (Crawford and Crawford, 1967).

In the present study lead concentrations over $0.1 \mathrm{p} . \mathrm{p} . \mathrm{m}$. were found in some hard as well as soft waters, but in hard water it is unlikely to be absorbed. Schroeder (1965) showed that the absorption by the body of trace elements such as lead, cadmium, zinc, etc. is inversely related to the concentrations of calcium in the medium. A recent experimental study using rats showed clearly that there was a greater absorption of lead when dietary calcium was low. The blood level of lead, with the low calcium diet and lead in drinking water, was about $200 \mu \mathrm{g} / 100 \mathrm{ml}$ of whole blood, whereas in those animals ingesting lead and a normal calcium intake it was about $50 \mu \mathrm{g} / 100 \mathrm{ml}$ (Six and Goyer, 1970). This means that a concentration of lead which may be harmless in a hard water may not be so in a soft water; in fact, hard water is protective against both the pick-up of lead from pipes and its absorption by the body. There is increasing appreciation in regard to many trace elements, including lead, that levels previously thought safe may not be so and that long exposure to small concentrations may be harmful. The problem is not of clinical or overt lead poisoning but the possibility that small doses of lead absorbed over a long period may be interfering with vital processes and rendering people less able to survive other stresses. Lead is known to interfere with the enzymes involved in the synthesis of haem, and significant reductions in enzyme activity have been found at blood lead levels currently thought to be within the normal range (Millar et al., 1970).

There is evidence that the cardiovascular system may be affected by excessive lead absorption. Angina pectoris in patients with chronic lead poisoning is mentioned briefly in 
earlier literature; the term "angina pectoris saturnina" was used by Hirschfeld (1926) in reporting cases of lead poisoning. More recently electrocardiographic changes have been reported in association with chest pain in cases of lead poisoning (Kosmider and Petelenz, 1961), and in a series of five fatal cases in children myocardial lesions-a subacute interstitial myocarditis-were thought to be responsible for the deaths of two and to have contributed to the death of the other three (Kline, 1960). Henderson and Inglis (1957) drew attention to high bone lead concentrations and a history of plumbism in childhood in a series of fatal cases of renal failure with hypertension-mainly young adults. Dingwall-Fordyce and Lane (1963) found more deaths from cerebrovascular disease in lead workers than in a control population.

We cannot say whether the absorption of lead from drinking water has been a factor in producing the differences in cardiovascular mortality between soft and hard water areas and, if so, how big a factor. It clearly does not "explain" the whole association between mortality and the softness of drinking water, but, as stated previously (Crawford et al., 1971), it could be an important contributory factor enhancing the correlations and causing the clearer picture found in Britain than in other countries.

As already stated, very effective corrective measures have been applied over a long period of time to many water supplies in England and Wales which would otherwise have been plumbosolvent; and there is some evidence in our studies of the county boroughs that some soft water towns, where effective treatment with lime has been applied for many years, have lower death rates than would be expected. In some supplies treatment to raise $\mathrm{pH}$ has started more recently and we are following the death rates in these towns. It is important that there is continued monitoring of supplies because of the great variability from house to house and from day to day in the same supply.

There is need for studies of possible mechanisms of how the lead ion may be operating in cardiovascular disease-for example, does the lead ion replace calcium or magnesium in vital electrochemical combinations or interfere in specific enzyme systems in the heart muscle ? If its role can be better identified it might yield important clues to aetiology of cardiovascular diseases.

A grant from the World Health Organization contributed to the cost of the analyses.

We wish to thank the medical officers of health of the study towns and their staffs for much help in organizing the study and in collecting samples; Dr. A. A. Smales, of the analytical division of the Atomic Energy Research Establishment, and his staff for the bone analyses; Dr. R. C. Hoather, of the Counties Public Health Laboratories, and his staff for the water analyses; and our colleagues and the staff of the M.R.C. Social Medicine Unit, in particular Mrs. D. Greystoke.

\section{References}

Beattie, A. D., Moore, M. R., Deveney, W. T., Miller, A. R., and Goldberg, A. (1972). British Medical fournal 2 491.

Crawford, M. D., and Crawford, T. (1969). Lancet, 2, 699.

Crawford, M. D., Gardner, M. J., and Morris, J. N. (1971). British Medical Bulletin, 27, 21 .

Crawford, M. D., and Morris, J. N. (1967). Lancet, 2, 1087.

Crawford, T., and Crawford, M. D. (1967). Lancet, 1, 229.

Dingwall-Fordyce, I., and Lane, R. E. (1963). British fournal of Industrial Medicine, 20, 313 .

Henderson, D. A., and Inglis, J. A. (1957). Australasian Annals of Medicine, 6,145 .

Hirschfeld, E. (1926). Zeitschrift für klinische Medizin, 104, 698.

Kline, T. S. (1960). American fournal of Diseases of Childhood, 99, 48.

Kosmider, S., and Petelenz, T. (1961). Polskie Archiwum Medycyny Wewnetrznej, 31, 1349.

Hislop, J. S., Parker, A., Spicer, G. S., and Webb, M. S. W. (1973). Atomic Energy Research Establishment Report No. 7321. London, H.M.S.O.

Millar, J. A., Battistini, V., Cumming, R. L. C., Carswell, F., and Goldberg A. (1970). Lancet, 2, 695 .

Reed, C. D., and Tolley, J. A. (1971). Journal of the Royal College of General Practitioners, 21, 289 .

Schroeder, H. A. (1965). Fournal of Chronic Diseases, 18, 217.

Six, K. M., and Goyer, R. A. (1970). Fournal of Laboratory and Clinical Medicine, 76, 933.

Stitt, F. W., Clayton, D. G., Crawford, M. D., and Morris, J. N. (1973) Lancet, 1,122

Wilson, A. T. (1966). Practitioner, 197, 77.

Wilson, A. T. (1967). Lancet, 1, 956.

World Health Organization (1971). International Standards for Drinking Water, Geneva, W.H.O.

\title{
Hypoxic Changes in Conducting Tissue of the Heart in Sudden Death in Infancy Syndrome
}

\author{
JAMES A. J. FERRIS
}

\begin{abstract}
Introduction
During the past 15 years much research has been devoted to the clinical entity now known as the "sudden death in infancy syndrome" ("cot death" or "crib death"). Recent efforts have been made to correlate the wide variety of aetiological theories (Bergman et al., 1970; Camps and Carpenter, 1972); the final mechanism of death, however, remains as yet unestablished. The present study reports the discovery of petechial haemorrhages in the region of the sinus node and the conducting tissue tracts leading to the atrioventricular node in a series of 11 sudden unexpected infant deaths.
\end{abstract}

\section{Materials and Methods}

Fifty cases of sudden death in infancy have been investigated so far. Only patients with a clinical history of sudden unexpected death in whom no precise cause could be found at necropsy were included. Because of the need to supply a cause of death to the coroner before full histological, bacteriological, and virus 